\title{
The Role of Social Networks on Shrimp Fishers' Access to Information and Gear in Rivers State
}

\author{
Gentle Wilson Komi ${ }^{1}$, Nelson Turyahabwe ${ }^{1}$, Prossy Isubikalu ${ }^{1}$, Amiye Francis ${ }^{2}$ and Aduabobo Ibitoru Hart ${ }^{3}$ \\ 1. Department of Extension and Innovation Studies, College of Agricultural and Environmental Sciences, Makerere University, P.O. \\ Box 7062, Kampala, Uganda \\ 2. Department of Fisheries, Faculty of Agriculture, University of Port Harcourt, PMB 5323, East-West Road, Port Harcourt, Nigeria \\ 3. Department of Animal \& Environmental Biology, Faculty of Science, University of Port Harcourt, PMB 5323, East-West Road, \\ Port Harcourt, Nigeria
}

\begin{abstract}
Access to information and appropriate fishing gear is fundamental to the protection and conservation of the fisheries resources to guarantee sustainable livelihood of the fishers. Social networks in eight fishing settlements of Rivers State were purposively selected to assess the role of networks on access and use of information and gear among the shrimp fishers. The cross-sectional study used mixed methods to elicit data. Data obtained were subjected to content analysis and MAXQDA 2018 software to generate project maps showing information and fishing gear accessed and used. Results show that 24.8\% (31) of respondents joined social network due to information sharing behavior of network members. Information was shared through one-on-one interactions, group meetings, fish buyers and phone calls. Out of the $96.8 \%$ (121) of respondents belonging to shrimp fishers' network, $23.2 \%$ attended meetings for at least four times a month while $22.4 \%$ attended meetings for more than four times a month. Information shared bordered on price of shrimps, weather and tide, fishing grounds and traps, water level, timing of fishing and processing techniques. Respondents revealed that information shared in their networks was correct, adequate and timely. Fishing gear accessed and used proficiently was dragnet, cast net and beach seine. In all, the evidence from the interview responses suggests that networks play a key role in shrimp fishers' access and use of information and fishing gear. Fishers are therefore, encouraged to be in one network or the other.
\end{abstract}

Key words: Acquisition, fisheries, resources, relationship, Niger Delta.

\section{Introduction}

Social networks serve as primary channels for the flow of information and resources that facilitate fishers' action [1]. Social interactions with friends, family, and co-workers also directly affect beliefs, decisions and behaviours. One of the most basic factors governing social network structure is the principle of "homophily". Homophily is a social selection process that describes the tendency for people to disproportionately form social ties with others most similar to themselves [2]. McPherson et al. [2] observed homophily in various types of social networks, especially for information sharing. Fishers

Corresponding author: Gentle Wilson Komi, research field: agricultural and rural innovation. naturally are closer to individuals and groups that provide helpful information needed for effective operations of their fishing enterprise. Access to fishing gear and the expertise in operation of the gear are valuable resources to be harnessed in fishing settlements.

It is, therefore, not certain how belonging to a shrimp fishers' social network enhances access to and use of resources such as fishing gear and information, which are expected to improve the living standards of the fishers. Hence, the role of social networks to the access and use of information and fishing gear by shrimp fishers was imperative. This study holds that social benefits such as improved living standards can be achieved through robust networks of fishers and other actors and their access to information as well as 
fishing gear.

According to Barnes-Mauthe et al. [3], the frequency of relevant information shared among fishers in their social network contributes to improved standard of living. The same authors assert that $90 \%$ of the fishers share information between one to three times in a week. Therefore, these networks could enhance exchange of information and other resources between actors in shrimp business. Social networks can provide increased access to scientific knowledge [4] and information on technological innovations. Information sharing has been found to improve the skills of fishers to achieve success in fishing [5].

\subsection{Statement of Research Problem}

Whereas, fishers' network influences access to information and use of fishing gear to the improvement of the shrimp fishers' living standards, it is not clear how the shrimp fishers in Rivers State obtain information and gear from their networks and how such networks influence the access and use of these resources. Therefore, this study seeks to establish the influence of social networks on shrimp fishers' access and use of information and fishing gear.

\subsection{Theoretical Framework}

The network theory of social capital [6] was the lens of this study. The theory holds that access to and use of resources is embedded in social networks. Social networks are patterns of vertical and horizontal relationships, or "ties", among actors [7], which can be comprised of various types of social relationships from casual to close bonds. From these social networks, fishers can accrue asset that can provide advantages to individuals or groups [6, 8].

\subsection{Conceptualization}

From a network perspective, the study systematically examines the functionality of social networks in terms of how belonging to a network enhances access to and use of resources such as: information and fishing gear which are expected to improve the living standards of the fishers. Therefore, this objective has two aspects: (1) information access and (2) fishing gear access and use.

\section{Materials and Methods}

\subsection{Study Area}

Social networks in eight fishing settlements belonging to three fishing axes of Rivers State were purposively selected for this study. Shrimp fishers from Borokiri axis (Ikpukulu, Andoni waterfront, Bundu waterside), Eagle Island axis (Nkpor village and Mgbuodohia) and Andoni axis (Okokiri, Oyorokoto and Muma) of Rivers State, shared information on their shrimp business. The study sites are in the Niger Delta Region (Fig. 1), which account for over $90 \%$ of the country's shrimp production [9, 10].

\subsection{Research Design}

A cross-sectional design was employed to elicit both qualitative and quantitative data. The qualitative approach obtained an in-depth understanding of how shrimp fishers' network influences access to and use of information pertaining to shrimps. The qualitative phase informed the development of the tools for the quantitative phase. For the qualitative approach, the study used focus group discussion (FGD) and key informant interview of shrimp fishers to identify what information and fishing gears are needed for the improved living standard and how people normally access these resources. The quantitative phase used a survey of systematically selected individual fishers to capture data about the networks they belong to, their access to and use of information and fishing gear.

\subsection{Study Population and Sampling Procedure}

Accessible shrimp fisher folks from Andoni and Borokiri waterfronts, and Eagle Island fishing settlements 


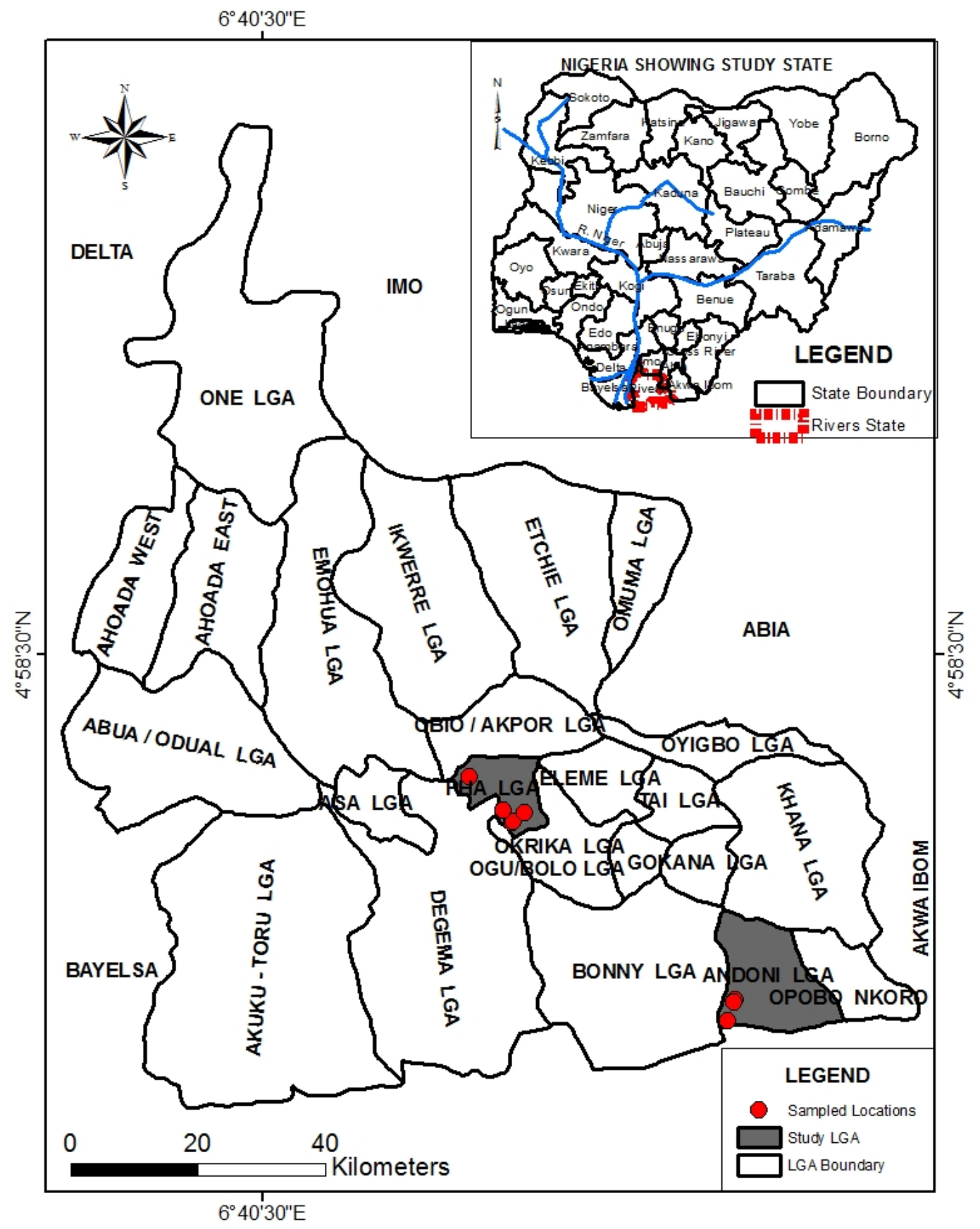

Fig. 1 Map of study sites.

of Rivers State who harvest shrimps from the wild and depend thereon for livelihood were surveyed. According to Oso and Onen [11], an accessible population is part of the target population which the researcher can reach, and out of which the researcher can draw a sample. Accessibility to fishers in the different fishing communities is encumbered by the difficult water terrains and requires more resources including time and finance [12].

\subsection{Individual Fisher's Survey}

For each of the three fishing axes purposively selected, a list of accessible shrimp fishers was generated by the community leaders as the sampling 
frame. The employed method was described by Krejcie and Morgan [13] in which 90\% to $95 \%$ of the accessible population was used to determine sample size. A questionnaire containing structured and semi-structured questions was administered to collect data on membership and participation in networks, access to and use of information, and other resources like fishing gear.

\subsection{Key Informant Interview}

Key informant interview was conducted with stakeholders including heads of research institutes, departments of fisheries, fisheries societies, extension services, government representatives, artisanal fisheries associations and community leaders.

\subsection{Data Analysis}

Qualitative content analysis defined as a research method for the subjective interpretation of the content of text data through the systematic classification process of coding and identifying themes or patterns [14] was adopted. Specifically, conventional content analysis was used.

The analysis was started with observation of the text data; codes were defined, and these codes were derived from the data. The reason was that the authors did not have any pre-determined relationship of the role of shrimp fishers' network on access to and use of information and fishing gear but rather derived such relationship from text data obtained from the field.

Similar process was conducted to identify the fishing gear that shrimp fishers' network members are able to access as a result of their membership to a network and how the network had influenced their ability to use the gear. Data were also subjected to MAXQDA 2018 software to generate project maps showing information and fishing gear accessed and used. Data were further subjected to descriptive statistics to quantify in percentage, responses from the field.

\section{Results and Discussion}

\subsection{The Role of Networks in Access to and Use of Information}

For the role of networks in information access and use, the interview questions were: (1) what information related to shrimp fishing do you share in your network? (2) where and how did you get the information from? Fig. 2 is a project map showing the responses to the first question while Fig. 3 is a project map showing the responses to the second question.

From Fig. 2, the information shared within a fisher's group includes price of shrimps (six references), weather and tide (five references), fishing grounds and traps (two references), water level (two references), timing of fishing (one reference) and processing techniques (one reference). Evidence: R1, the chairperson, Fisheries Society of Nigeria Rivers State Chapter, said that: "Information shared includes; timing of fishing, water level, tide, the traps to use, price and processing techniques..." Similarly, R6, an old experienced fisherman, stated that "Information shared is on price and tide." Also, $\mathrm{R} 5$, the chairman of a fishing settlement, said that: "Information shared in the network is on cost of fishing gear and price of shrimp."

In Fig. 3, the respondents identified about five sources of information that are shared within fisher's group which include the market (five references), experienced fishers (three references), government agencies (three references), media (two references) and friends (two references).

Evidence: R5 stated that: "...This information is gotten from the market.” Likewise, R4, a female fisher said that: "...Such information is gotten from other shrimp fishers or by one's expertise.” Also, R1 stated that: "...Information is gotten from experienced fishers who have been in the business for years.” 


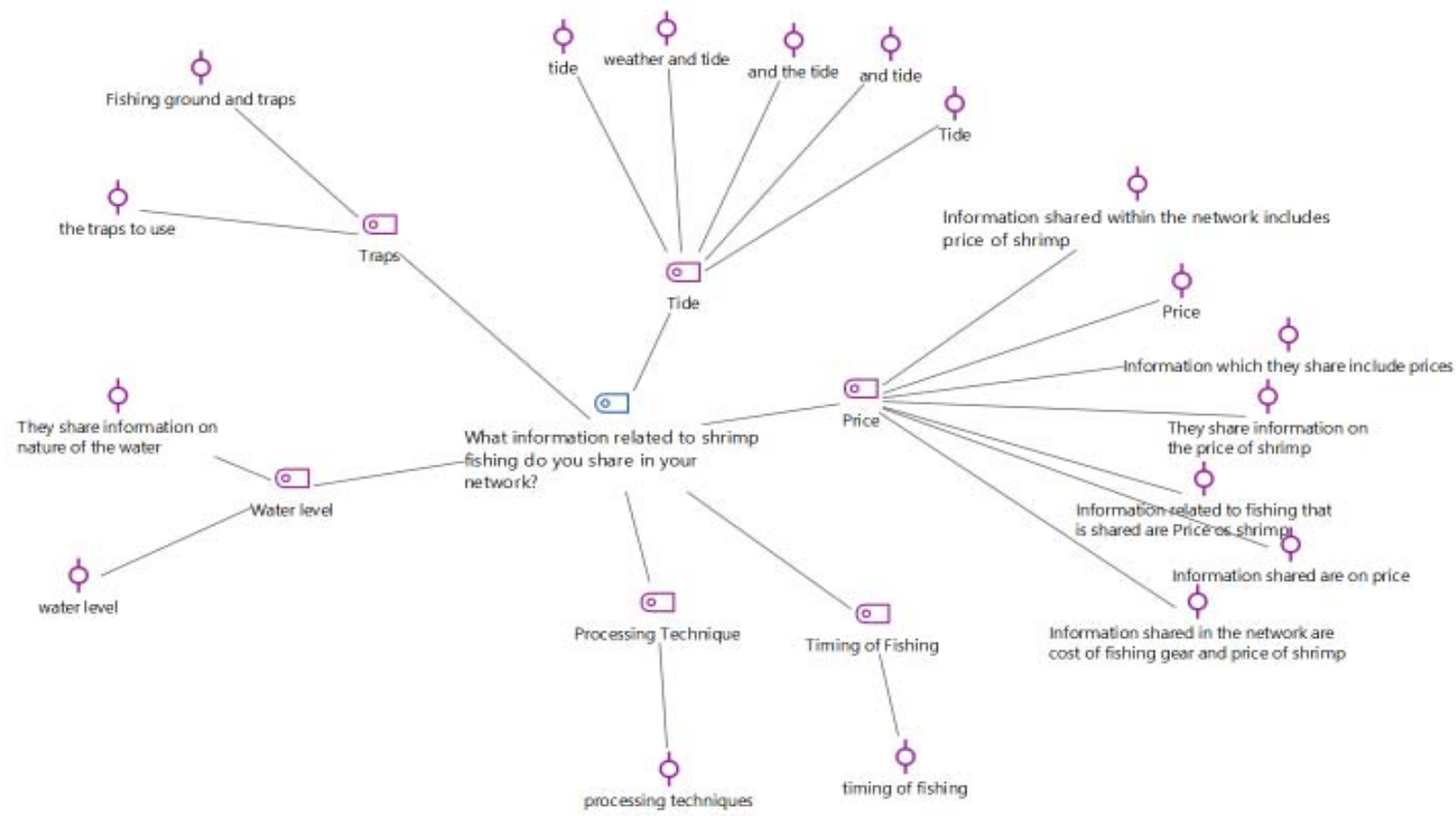

Fig. 2 Project map for information shared within a fisher's group. Source: MAXQDA 2018 output based on interview data.

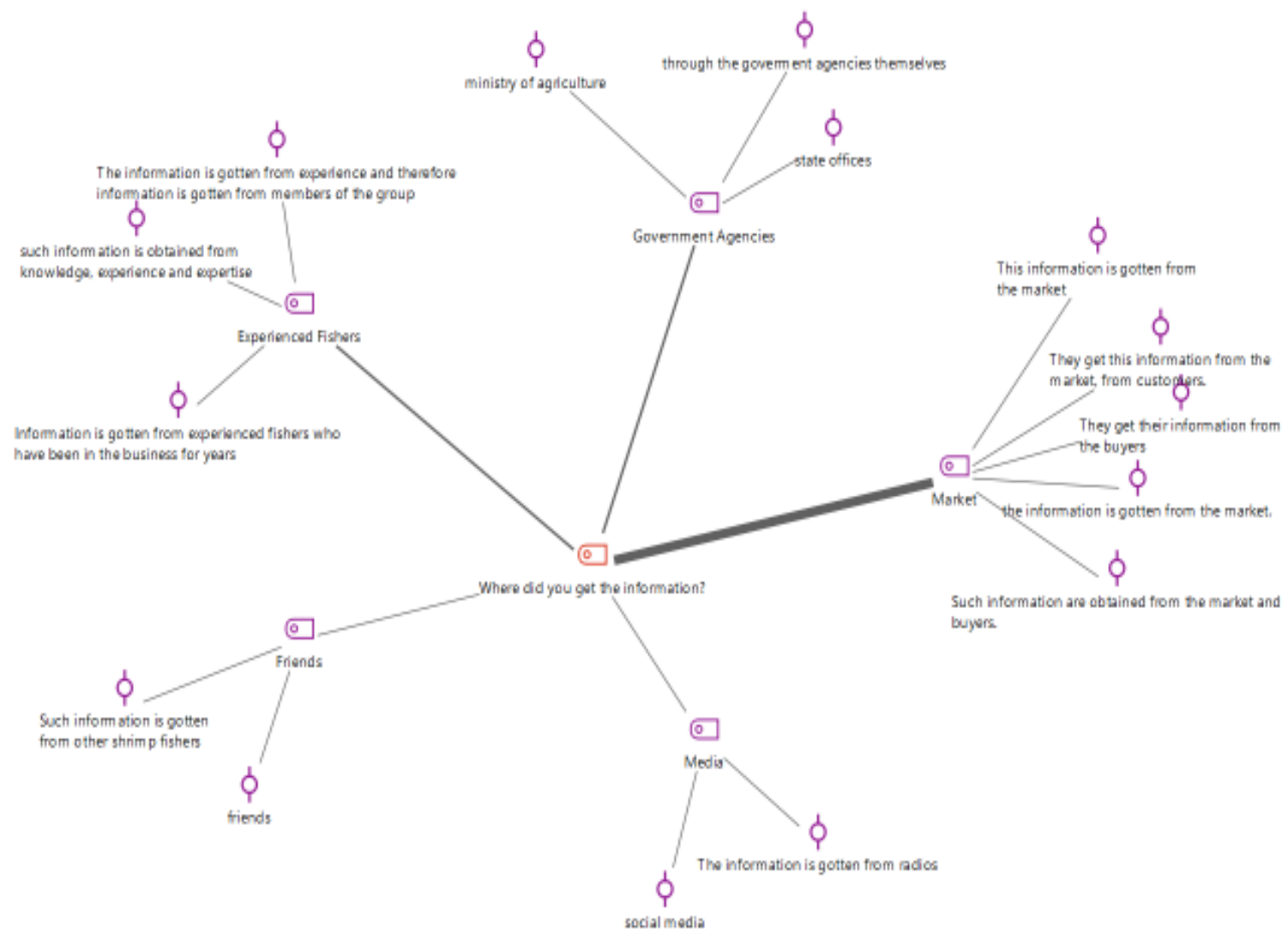

Fig. 3 Project map for source of information shared.

Source: MAXQDA 2018 output based on interview data. 
3.2 The Role of Networks in Access to and Use of Fishing Gear

For the role of networks in access to and use of fishing gear, the interview questions are: (1) which fishing gear are you able to use with the help of your co-fisher? (2) how has your network helped you to access the fishing gear? (3) where do you access the fishing gear? Fig. 4 is a project map showing the responses to the first question. Fig. 5 is a project map showing the responses to the second question. Fig. 6 is a project map showing the responses to the third question.

From Fig. 4, networks help individual fishers to use different kinds of fishing gear including drag net (five references), cast net (three references), long line (three references), beach seine net ('otutogbor' two references) and mini trawler net with wooden frame attached to a boat ('nkoto' two references).

From Fig. 5, fishers' networks help individual members to access fishing gear by providing market information (six references), loan facility (four references), contributions (two references), credit purchase (one reference) and cost reducing (one reference). Evidence: R6, an old experienced fisherman, said that: "Network helps members to access fishing gear by providing information on market location and price." Similarly, R1, chairperson, Fisheries Society of Nigeria Rivers State Chapter said that: "Network helps to reduce the cost of purchase since they buy in bulk from input supplier."

Also, R3, the vice chairman Ikpukulu fishing settlement, said that: "Members are allowed to borrow money from the group to buy fishing gear.” Finally, R7, an experienced old female shrimp fisher at Bundu water side, said that: "The network helps members in accessing fishing gear by contributing for them.”

From Fig. 6, fishing gear were mostly accessed from sellers in the market. Evidence: R2, assistant director, Fisheries and Aquaculture, Nigerian Institute

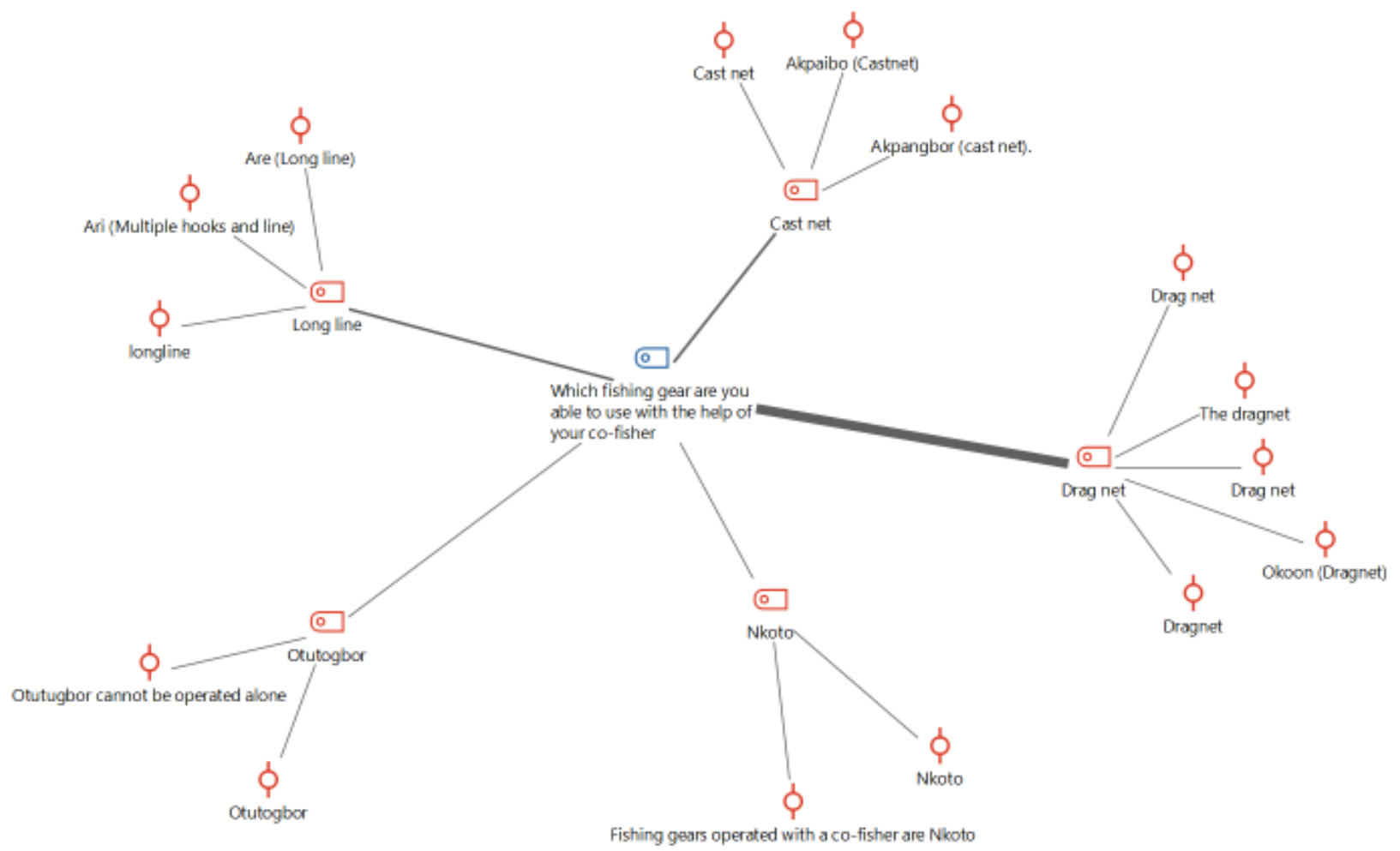

Fig. 4 Project map for use of fishing gear.

Source: MAXQDA 2018 output based on interview data. 

and Gear in Rivers State

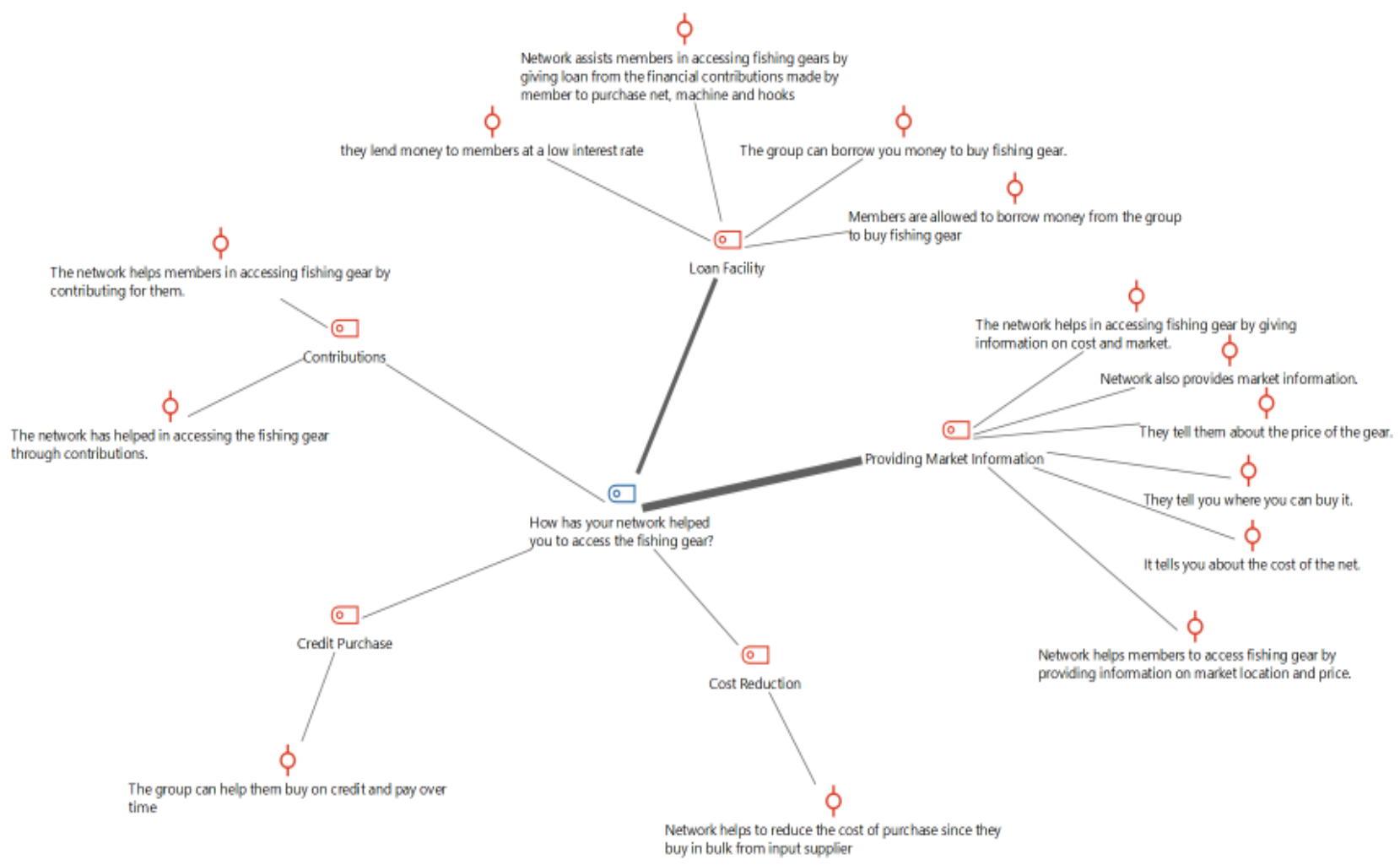

Fig. 5 Project map for access to fishing gear.

Source: MAXQDA 2018 output based on interview data.

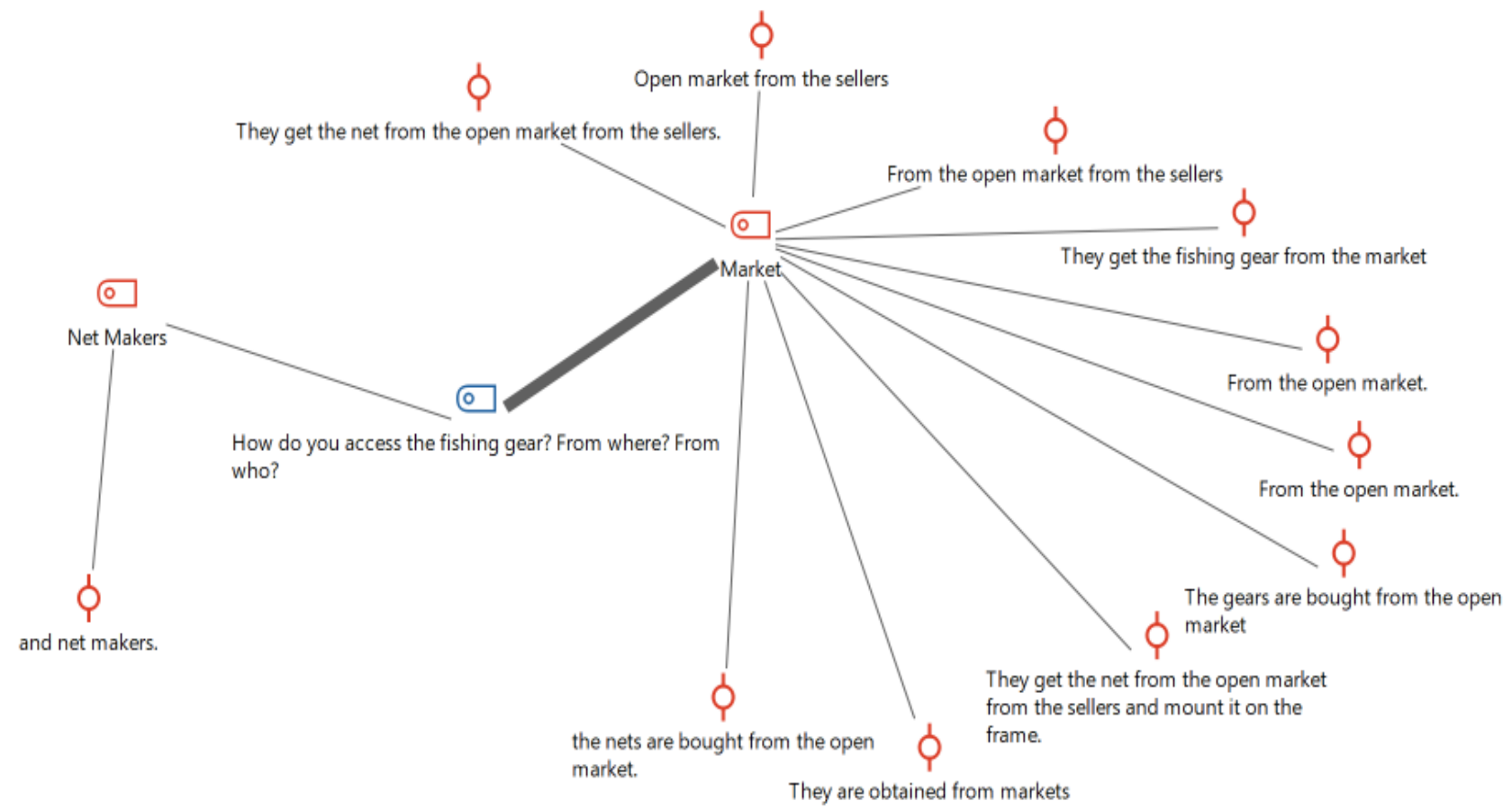

Fig. 6 Project map for source of fishing gear.

Source: MAXQDA 2018 output based on interview data. 
for Oceanography and Marine Research, said that: "They get the net from the open market from the sellers and mount it on the frame.” Similarly, R3, vice chairman Ikpukulu fishing settlement, said that: "The gears are bought from the open market and net makers."

On the other hand, one-third of fishers who joined a group or network do so for search of information (Table 1). Shrimp fishers belonging to the Andoni axis of Rivers State had more fishers involved in networks (52\%). This further suggests the viability of the industry as well as the economic potential in shrimp fisheries among Andoni fishers.

\subsection{Access to Information through Connections}

The respondents said that connections occur for the purpose of information shared on market price and allow for exchange of shrimp with fish or other products. Networking allows fishers to negotiate for fishing grounds to avoid conflicts and to have a common front against events that affect their common interest (thus ensuring a better fishing experience). Key informants agreed that connections exist within communities and these connections are between fishers and processors as well as processors and marketers (middlemen). Challenges faced in accessing information include poor or absence of communication network service and high cost of water transport (Fig.7). Some informants were of the view that high cost of water transport limits access among groups; however, they agreed that when fishers have access to information and sources of information, maintaining such connections and sharing the information did not pose much challenge. Some fishing groups noted that encroachment into fishing grounds poses a great challenge to them and controversy often arises between hardboard engine and the canoe fishers.

The benefits enjoyed as a result of connecting with groups include: the right of purchase, since they have first hand information on fish catch but also can buy shrimp on credit. Benefits derived from connection also include timely information on fishing ground. In addition, new friends and acquaintances are formed and information access becomes easier.

Table 1 Information searching behavior of shrimp fishers in three fishing axes of Rivers State.

\begin{tabular}{lll}
\hline Variables & Frequency & Percentage \\
\hline Do you belong to a group or network? & 121 & 96.8 \\
Yes & 4 & 3.2 \\
No & & \\
\hline What attracted your membership? & 31 & 24.8 \\
Information searching \& sharing behavior of group members & 75.2 \\
Yes & 94 & 52.0 \\
No & & 19.2 \\
\hline Shrimp fishing axes & 65 & 28.8 \\
\hline Andoni & 24 & 12.8 \\
Borokiri & 36 & 20.8 \\
Eagle Island & & 15.2 \\
Number of times interacting with other network members in a month & 16 & 23.2 \\
\hline Once & 26 & 22.4 \\
Twice & 19 & 4.8 \\
Three times & 29 & \\
Four times & 28 & \\
More than four times & 6 & \\
No time & & \\
\hline
\end{tabular}




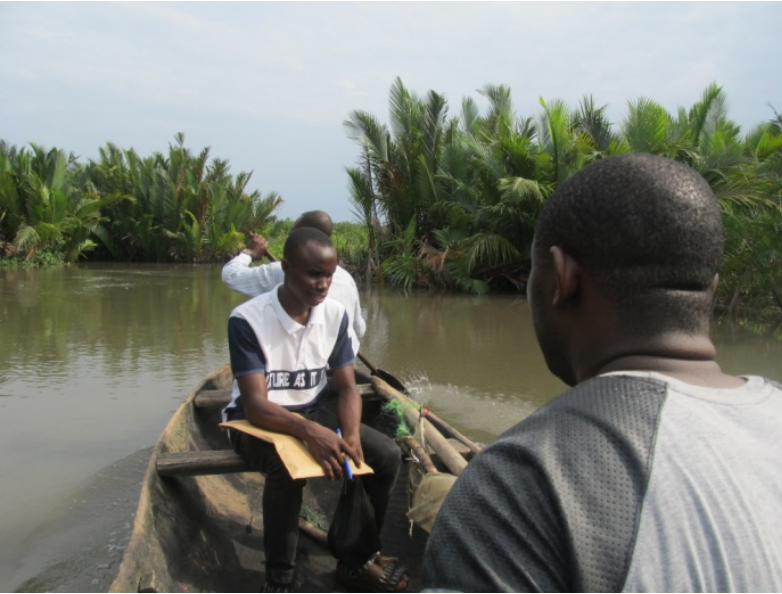

(a)

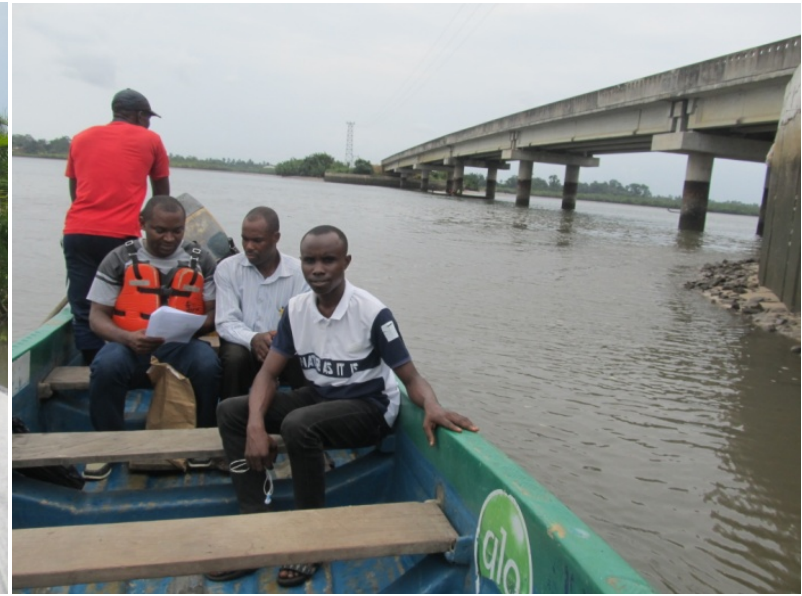

(b)

Fig. 7 Transport system in fishing settlements in Rivers State.

\subsection{Sources of Information Related to Shrimp Fishing Shared by Respondents}

The respondents stated that the information shared was gotten from experienced fishers who have been in the business for years. Some respondents said the information was gotten from the market, buyers, radio, Ministry of Agriculture, social media, state offices, and friends and from agencies. Most of this information was gotten from direct contact.

Respondents indicated that information shared (Fig. 8) includes time of fishing, water level, tide, the traps used, pricing information, fishing gear and processing techniques. It was also gathered that fishers share information on how to improve their daily catch, source of net, grant available for their business, and organizations available that can contribute shares to their business.

FGD revealed that they share information on the price of shrimps, nature of tide, cost of fishing gear, experience and expertise. Fisher groups indicated they got information from buyers through direct contacts and phone calls.

\subsection{Frequency of Sharing Information}

Respondents stated that they share information as often as they meet and as the information comes. However, the frequency of information sharing varies between groups as informants indicated that some share information twice a week, others thrice a week, twice a month and at every fishing day (6 $\mathrm{d}$ in a week). Most fisher groups indicated they share information two times a week, once a week, daily, while others said every two weeks.

3.6 Relevance of Information Shared in the Network to Shrimp Business

Respondents indicated that information shared was correct, accurate, timely, relevant and adequate. They affirmed that "information is disseminated as it is the source of their living". However, most informants claimed that though information shared was relevant, sometimes it can be deceptive as other fishers use them to draw attention away from their fishing grounds. Responses from the FGD revealed that information shared in their network is correct, adequate and timely. They also indicated that correctness of the information was adjudged based on the experience of the fishers.

\subsection{Fishing Gear Operated (or in Use)}

The respondents indicated that cast net, long line, seine net, drag net, Nkoto (a variant of mini trawler net with wooden frame attached to a boat), Gbileme (sunken cast net), Otutugbor (beach seine net), Akpangbo (looks like a bag or scoop net with very 


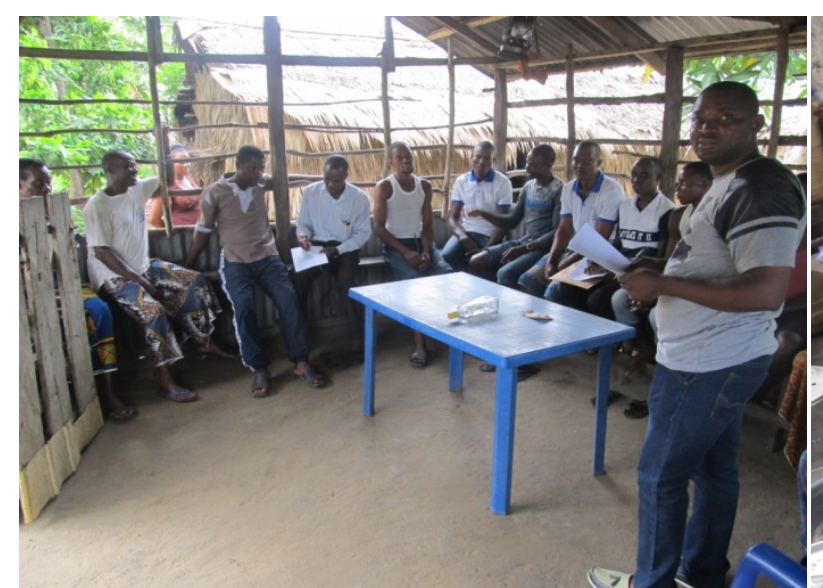

(a)

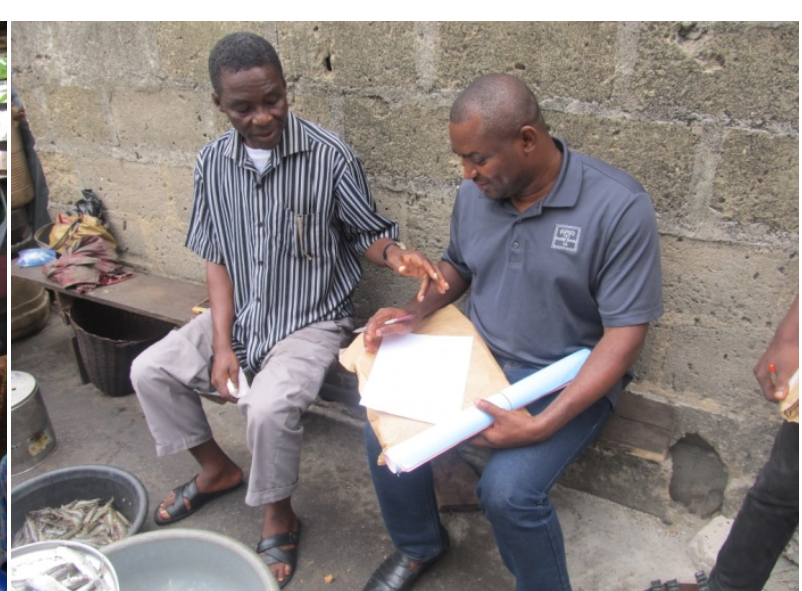

(b)

Fig. 8 Focus group discussion with shrimp fishers in Andoni axis (a) and an in-depth interview with a community leader (b).

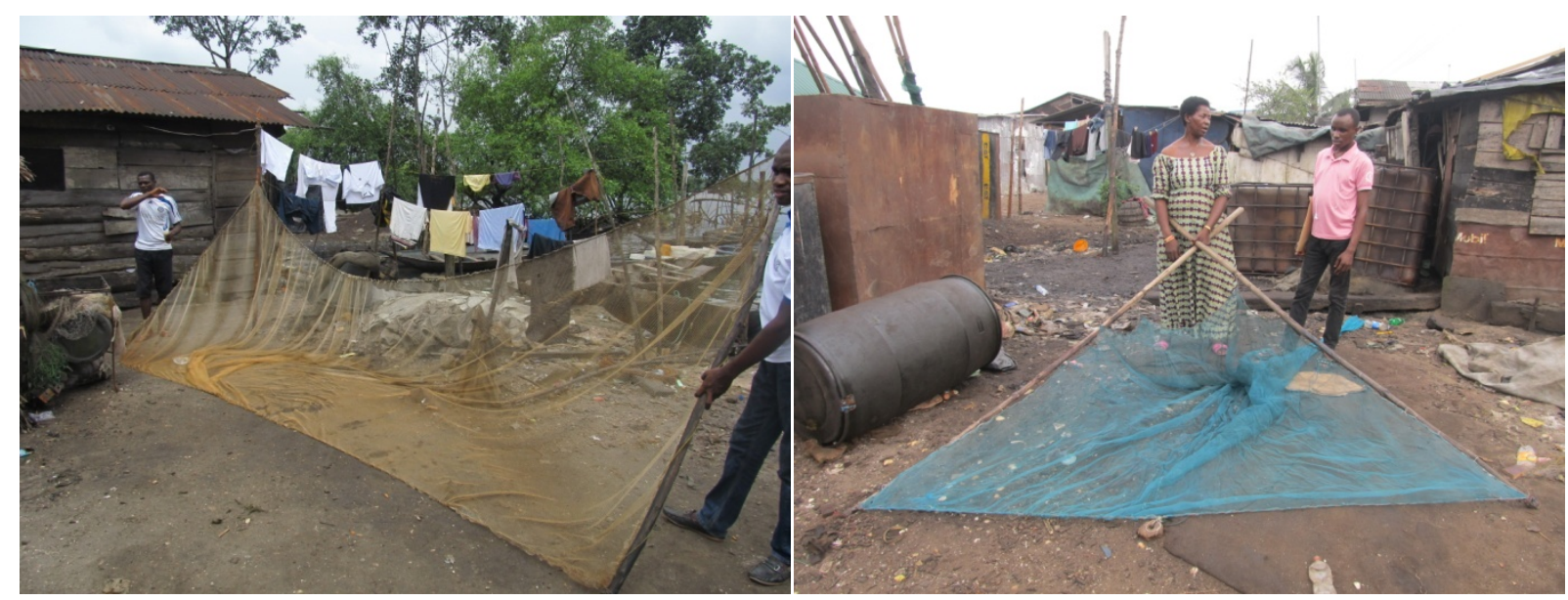

Fig. 9 Shrimp fishers demonstrating their proficiency in the use of gear.

small meshes), Ari (multiple hooks and line), scoop net, Onyima (a mini trawler net attached to boat with nets of different mesh sizes) and Ngoro (drag net mostly used by women) were all in use.

Results further revealed that fishers operate fishing gears such as hand pulling canoe and throw net of different mesh sizes (“sopak”, “Teller”).

\subsection{Ability to Use Fishing Gear}

Respondents (Fig. 9) affirmed "we use our fishing gear very well and excellently well.” However, others indicated they operate all fishing gears excellently well.

\subsection{Frequency of Information Shared}

Fisher groups indicated varied times in which they shared information to include: two times in a week, once weekly, daily and every two weeks. This was mainly done during meetings.

\subsection{Relevance of Information Shared in the Network}

Response from the FGD revealed that information shared in their network is correct, adequate and timely. They also indicated that correctness of the information is based on the experience of fishers.

According to Barnes et al. [1] having a better understanding of social structures and effective communication across segregated networks has the potential to contribute toward more sustainable environmental outcomes. Similarly, access to information and appropriate fishing gear goes a long way in ensuring protection and conservation of the 
fisheries resources which in turn guarantee sustainable livelihood of the fishers.

Campbell and Barlowt [15] noted that social networks might have important positive and negative roles in its members. For example in a positive sense, development of a strong personal relationship between the technology donor and the recipient is often crucial whereas in a negative sense nepotism it could lead to exclusion of some people who could have benefited.

According to Lebel et al. [16], social network of shrimp farmers was useful in eliminating imbibed errors on their trade and provides room for acquisition of expertise and gaining from experience of network members. These networks also formed a platform engaged in constant evaluation of performance and progressed towards sustainable livelihood. Workshops, clubs and seminar sessions normally spring up from such networks.

The lessons were learned from the world's greatest exporters of shrimps: Thailand and Mexico can enrich shrimp business in Rivers State, Nigeria. The government and industries normally associate with these networks of shrimp farmers from both countries; the importance of sharing information among members has proved more useful than when information is kept secret.

Though there are multiple sources of information media [17], ranging from print media, electronic media, telephone, physical contact through group meetings and personal conversation, fishers in Rivers State are unable to utilize all the sources. Shrimp fishers however share information through limited sources. The reasons are not farfetched due to the peculiarity of their underdeveloped, waterlogged, rural setting, thus making information sharing difficult. Social network is, however, a viable means of dissemination of information.

\section{Conclusions}

The success of information sharing within the social network in Rivers State lies in frequent contact of the fishers with one another. However, the reliability of information shared was dependent on the tacit knowledge of the fishers. Hence, the relevance of the information was adjudged based on experience. Shrimp fishers can be so used to water tides that they tell you the time without looking at the watch. Hence, they alluded to the correctness, adequacy and timeliness of the information they shared.

Access and use of fishing gear had been a serious challenge to fishers as this was their stock-in-trade or working tool. Social networks however had proven to provide succor by giving soft loan to network members to enable them to acquire nets, boats and their accessories. It is therefore obvious the role of networks in alleviating the burden of access to gear and dissemination of vital information for shrimp fishing operations.

In the long run, the usefulness of networks among shrimp fishers includes the following: gaining expertise and correct information for sustained livelihood through shrimp fishing. The network is also a platform on which government, researchers and the private sectors can catch on for socio-economic advancement projects and efforts. In all, the evidence from the interview responses suggests that networks play a key role in shrimp fishers' access to and use of information and fishing gear.

\section{Acknowledgments}

Special appreciation goes to the Carnegie Corporation of New York for funding the programme through the Regional Forum for Capacity Building in Agriculture (RUFORUM), who coordinated the grant (RU/2012/DRS/01).

\section{References}

[1] Barnes, M. L., Lynham, J., Kalberg, K., and Leung, P. S. 2016. "Social Networks and Environmental Outcomes." Proceedings of the National Academy of Sciences 113 (23): 6466-71. doi:10.1073/pnas.1523245113.

[2] McPherson, M., Smith-Lovin, L., and Cook, J. M. 2001. "Birds of a Feather: Homophily in Social Networks." Annu Rev Sociol 27: 415-44. 
[3] Barnes-Mauthe, M., Arita, S., Allen, S. D., Gray, S. A., and Leung, P. S. 2013. "The Influence of Ethnic Diversity on Social Network Structure in a Common-Pool Resource System: Implications for Collaborative Management.” Ecology and Society 18 (1): 23. https://doi.org/10.5751/ES-05295-180123.

[4] Grafton, R. Q. 2005. "Social Capital and Fisheries Governance.” Ocean \& Coastal Management 48 (9-10): 753-66.

[5] Turner, R. A., Polunin, N. V. C., and Stead, S. M. 2014. “Social Networks and Fishers' Behavior: Exploring the Links between Information Flow and Fishing Success in the Northumberland Lobster Fishery." Ecology and $\begin{array}{llll}\text { Society } & 19 & \text { (2): } & \end{array}$ http://dx.doi.org/10.5751/ES-06456-190238.

[6] Lin, N. 1999. "Building a Network Theory of Social Capital.” Connections 22 (1): 28-51.

[7] Moore, M., and Westley, F. 2011. "Surmountable Chasms: Networks and Social Innovation for Resilient Systems." Ecology and Society 16 (1): 5. http://www.ecologyandsociety.org/vol16/iss1/art5/.

[8] Coleman, J. S. 1988. "Social Capital in the Creation of Human Capital.” American Journal of Sociology 94: 95-120.

[9] FAO. 2000. Report of the Four GEF/UNEP/FAO Regional Workshop on Reducing the Impact of Tropical Shrimp Trawl Fisheries, Dec. 15-17, 1999. Lagos, Nigeria, FAO Corporate Document Repository, Fisheries and Aquaculture Department. FAO Fisheries Report No. 627.
[10] Nwosu, F. M., Ita, E. O., and Enin, U. I. 2011. "Fisheries Management in Nigeria: A Case Study of the Marine Fisheries Policy.” International Research Journal of Agricultural Science and Soil Science 1 (3): 70-6.

[11] Oso, W. Y., and Onen, D. 2009. General Guide to Writing Research Proposal and Report. Nairobi: The Jomo Kenyatta Foundation.

[12] Lawal, J.-S., Obatola, P. O., Giwa, E. J., and Alhaji, T. A. 2016. "Socio-Economic Analysis of Artisanal Fishing Operation in West and East Axes of Lagos State, Nigeria." World Journal of Agricultural Research 4 (1): 31-5.

[13] Krejcie, R. V., and Morgan, D. W. 1970. "Determining Sample Size for Research Activities.” Educational and Psychological Measurement 30: 607-10.

[14] Hsieh, H., and Shannon, S. E. 2005. "Three Approaches to Qualitative Content Analysis.” Qualitative Health Research 15 (9): 1277-88.

[15] Campbell, I., and Barlowt, C. 2017. Knowledge Transfer in International Water Resource Management-Six Challenges. South Balckburn: Rhithroecology Pty Ltd, 293-303.

[16] Lebel, L., Garden, P., Luers, A., Manuel-Navarrete, D., and Giap, D. H. 2016. "Knowledge and Innovation Relationships in the Shrimp Industry in Thailand and Mexico." Proceedings of the National Academy of Science of the United States of America 113 (17): 4585-90. https://doi.org/10.1073/pnas.0900555106.

[17] Gurevitch, J., Koricheva, J., Nakagawa, S., and Stewart, G. 2018. "Meta-Analysis and the Science of Research Synthesis. Research Review.” Nature 555: 175-82. 